\title{
LA OBRA LÍRICA AUTÓGRAFA DE BANCES CANDAMO
}

\author{
DAVINIA RODRÍGUEZ ORTEGA \\ Universidad Pública de Navarra
}

Resumen

El presente artículo estudia la disposición externa, la organización interna y las intervenciones autoriales del manuscrito autógrafo 2248 titulado Obras lyricas, dedicado a Mariana de Borja y Cerceda y fechado en 1715 que conserva en la BNE y recoge buena parte de la obra lírica de Bances Candamo.

Palabras clave: Bances Candamo, poesía, autógrafo, Obras lyricas.

\section{THE AUTOGRAPHIC POETRY OF BANCES CANDAMO}

\section{Abstract}

This article studies the external layout, the internal organization, and the authorship interventions of the autographic manuscript 2248 entitled Obras lyricas, dedicated to Mariana de Borja y Cerceda and dated in 1715, preserved at the National Library of Spain, which contains much of the poetry of Bances Candamo.

Keywords: Bances Candamo, poetry, autographic, Obras lyricas.

\section{INTRODUCCIÓN}

La obra autógrafa conservada del poeta áulico Bances Candamo se reduce a un breve número de piezas pertenecientes a distintos géneros literarios: teatro, poesía, ensayo y epistolar. El corpus de estas últimas consta de solo tres documentos conservados en la BNE en los que el asturiano se dirige a don Antonio Martín Álvarez de Toledo (IX Duque de 
Alba), junto con algunas copias fragmentadas que fueron rescatadas de los varios incendios y traslados sufridos por el Archivo de los Duques de Alba, ahora situado en el madrileño Palacio de Liria. Respecto a los demás autógrafos, dentro de los fondos custodiados en la BNE, algunos de ellos han gozado de cierto interés por parte de los investigadores y cuentan con una edición moderna. Así, es posible enumerar el «Entremés de las visiones» (ms. 16575), con estudio y edición crítica a cargo de Arellano (1987), que precedió al auto sacramental (también de Bances Candamo) titulado El gran químico del mundo. Como muestra del género ensayístico, se conserva un ejemplar de mano del poeta de su gran obra Teatro de los teatros de los pasados y presentes siglos (ms. 17549), teoría dramática inacabada y editada por Moir (1970). Mientras, las epístolas de Bances Candamo han sido estudiadas en detalle por Zugasti (2009; en prensa). Por último, encontramos un volumen titulado genéricamente Obras (ms. 2248) con fecha de 1715 que recoge algunos de los escritos poéticos del autor asturiano. Es precisamente este último motivo el que centrará nuestro interés en este artículo, por las razones que se explicarán a continuación.

La crítica especializada se ha dedicado ampliamente a la obra dramática según se desprende de la abundante bibliografía recogida por Duarte et al. (2010) y publicada en el marco de los proyectos del GRISO. Dentro de las entradas aquí recogidas podríamos destacar los pioneros análisis de Arellano (1988) y Suárez (1992). Del mismo modo, aunque en menor medida al tratarse de un conjunto de obras más reducido, diversos estudiosos han prestado atención a la poesía de Bances Candamo, entre los que cabría destacar el interés de Gutiérrez (Bances Candamo, 1949)², García Castañón (1990; Bances Candamo, 2004), Echevarren (2013), Oteiza (2017; 2020) y Duarte (en prensa). En último lugar, en relación a los aspectos biobiliográficos de Bances, sigue siendo esencial el volumen de CuervoArango (1916), completado por Del Río Marín (1949), Zugasti (2009) y Echevarren (2013), sumando aspectos concretos y desconocidos hasta el momento de la vida del poeta. Al ser tan extensamente conocida esta información, no me detendré a recogerla en estas páginas, más allá de mencionar que Bances Candamo fue un poeta de la corte y uno de los últimos

${ }^{1}$ Este investigador realiza una edición crítica de Bances Candamo (1720) que comprende algunos de los textos incluidos en el autógrafo junto a otros nuevos. La nómina de poemas contenidos en uno y otro volumen serán estudiados en las siguientes páginas. 
representantes del Siglo de Oro español, con una escritura ya inclinada hacia el neoclasicismo y la Ilustración (Sebold, 1997; Suárez, 1992)².

Sin embargo, dentro de toda la bibliografía relativa a Bances Candamo, ninguna investigación se ha centrado en estudiar en profundidad los testimonios autógrafos del poeta en lo que concierne a las intervenciones y correcciones del autor (reelaboraciones, cuestiones métricas, supresiones, añadidos, etc.), disposición externa del documento (¿cómo se distribuyen los textos compilados en la página escrita?) y organización interna (¿qué textos contiene y cómo se organizan?). Para responder a estas cuestiones la condición de las Obras del manuscrito 2248 es privilegiada respecto al resto de autógrafos conservados: uno bastante limpio (Teatro de los teatros) y otros muy breves («Entremés de las visiones» y «Cartas»). Y precisamente a estas preguntas intentaremos dar respuesta.

Si bien los análisis sobre el modo de proceder de nuestro creador frente a su autógrafo son aún inexistentes (y aquí radica la novedad de este enfoque), existen referencias importantes acerca de las obras de Lope de Vega y Calderón de la Barca. Como podremos comprobar a continuación, todas son investigaciones de reciente aparición, aspecto que señala el interés actual por la materia. Un estudio clave sobre el Fénix es el monográfico de Crivellari (2013) sobre las marcas de segmentación en las comedias autógrafas, al que siguió otro texto con la misma temática en los autos sacramentales (Crivellari, 2018). La situación de las comedias autógrafas de Calderón de la Barca también ha sido abordada en detalle por Kroll (2017) y Hernando Morata (2015), mientras que Arellano (2015), Escudero Baztán (2020) y Rodríguez Ortega (2020) se han interesado por las piezas sacramentales.

\section{DISPOSICIÓN EXTERNA}

Según se puede comprobar con facilidad al revisar el ms. 2248, autógrafo de las Obras de Bances Candamo, nos encontramos ante un volumen facticio, creado a partir de cuartillas individuales donde están

\footnotetext{
${ }^{2}$ Es pertinente, sin embargo, reparar aquí en el estudio de Checa Beltrán (2012) que compara con múltiples ejemplos la idea de teatro que tenían Bances Candamo y Luzán, para concluir que, mientras el primero de ellos aún pertenecía al modo de hacer del Siglo de Oro, el segundo estaba de pleno integrado en el Neoclasicismo.
} 
recogidas las diversas composiciones poéticas ofrecidas, entre las cuales predominan los sonetos ${ }^{3}$, los romances y los romances heroicos. De hecho, gracias a la lista completa de los textos que comprenden Obras líricas referenciada por Oteiza (2017: 455-458), hemos podido elaborar fácilmente una relación de los poemas que aparecen en el autógrafo:

\section{METROS CULTOS}

Soneto I. Epitafio a la majestad del señor Carlos II, «Yace un monarca en este monumento» (fol. 1r) $)^{4}$.

Soneto II. «Descansa aquí, no yace, oh peregrino» (fol. 2r).

Soneto III. «De la cumbre del Etna monumento» (fol. 3r).

Soneto IV. "Ofendiome Amarili y yo quejoso» (fol. 3v).

Soneto V. A unos cañaverales: alude a la transformación de Syringa, «Hermosa ninfa, ya verde y amena» (fols. $3 \mathrm{r}-4 \mathrm{v}$ ).

Soneto VI. «Arrebatado en águila de pino» (fol. 4v).

Soneto VII. "A la madre de Amor mientras buscando»: lleva fecha de julio de 1695 (fol. 25r).

Soneto VIII. «De qué me sirve, Amor, fingir enojos»: lleva fecha de julio de 1695 (fol. 26r).

Soneto IX. «Llora el alba, lloraba Fili un día» (fol. 27r).

Soneto X. «Helarse con el fuego, arder al yelo» (fols. 27r-27v).

Soneto XI. «En el papel del aire el otro día» (fols. 28r-28v).

Soneto XIII. «Jacob por la hermosura de Raquel» (fol. 47r).

Soneto XIV. «Por error de tu cielo, Fili bella» (fol. 47r).

\footnotetext{
${ }^{3}$ García Castañón (1999: 711) ya destaca este interés de Bances Candamo por dicha composición poética y su énfasis en su escritura, y acudiendo a las palabras de Cascales dice: «El soneto era -y sigue siéndolo hoy- la prueba de fuego para cualquier aspirante a los laureles de poeta, y muchos osados componían sonetos: "La poesía más común que hoy tiene España, y aun toda la cristiandad... es el soneto. El docto y el indocto, quienquiera, se atreve a poner las manos en el sagrado soneto, sin creer que por ello el que no está ordenado del divino Apolo queda irregular y excomulgado ipse iure"».

4 La paginación del autógrafo no es consistente, pues, a continuación del fol. 4, se pasa al fol. 13, momento en el cual también cambia la forma métrica; así, tras una secuencia de sonetos, se inserta una carta-ovillejo.
} 
Soneto XV. Al arroyo de Torcón, que ha cavado gran profundidad en las peñas donde se precipita, «Este florido arroyo caudaloso» (fol. 47v)

Soneto XVI. Si hay celos en palacio, «Si el que adora beldades superiores» (fol. 47v).

Soneto XVII. Vida de la aldea, «Los que dicen que es vida sosegada» (fol. 57v).

Soneto XVIII. Vida pastoril, «Gana medio leyendo las extrañas» (fol. 58v).

Soneto XIX. "Como el enfermo que con sed ardiente» (fols. 59r-59v).

Soneto XX. «Qué haces allá de amante embelesado» (fol. 60r).

Soneto XXI. A la pragmática que se dijo salía quitando las cabelleras, «No salió la pragmática severa» (fols. 61r-61v).

Carta-ovillejo. "Señor excelentísimo y mi tío», son 15 estrofas sexta rima que intercalan 19 redondillas (fols. 13r-16v).

Décimas I. «Hurtó en reflejo el pintor» (fols. 19v-20v).

Décimas II. "Contra ti sean los enojos» (fols. 23v-24v).

Silva. «Precipitaba Apolo de los montes», al final se anota: «Dejola así el autor, año de 1690». Son 11 estrofas de endecasílabos y heptasílabos. Cada estrofa tiene 6 versos, excepto una de 4 versos y otra de 5 (fols. 62r-63r).

\section{METROS POPULARES}

Romance heroico I. Oración académica, «Aquella de la lid rota celada» (fols. 17r19r).

Romance heroico II. Llora la gloriosa muerte del excelentísimo señor don Manuel Diego López de Zúñiga, que sucedió a 16 de julio, de un mosquetazo que recibió en un asalto de Buda, capital de Hungría, año de 1686, "Qué monstruo alado con siniestro vuelo» (fols. $45 \mathrm{v}-46 \mathrm{v}$ ).

Romance heroico III. A una más que peregrina imagen de santa María Magdalena, del insigne escultor Pedro de Mena, hijo de Granada y vecino de Málaga, donde está sepultado, "Qué tronco es este, que elevando informa» (fols. 49r-51v).

Romance I. «Después que por largos días», fechado en Ocaña el 15 de septiembre de 1697 (fols. 29r-32v).

Romance III. Respondiendo a D. Antonio de Zamora, oficial de la Secretaría de Indias, habiéndole participado la muerte de la Serenísima Reina nuestra señora doña María Luisa de Borbón, «Para responderte, amigo» (fols. 40r-45v). 
Romance IV. A la imagen de Nuestra Señora de la Soledad, que está en la Victoria de Madrid, «Aquel angustiado vulto» (fols. 48r-48v).

Romance V. Deja la majestad de Carlos Segundo el coche al sacerdote que llevaba el santísimo sacramento a un enfermo. Sucedió a 23 de enero de 1685. Pondérase que la destruición del imperio romano la causó la idolatría, y su exaltación el celo de la religión católica, «Aquel arrogante Imperio» (fols. $51 v-52 v)$.

Romance IX. Al conde de Clavijo, señor de la Aldegüela, «Escuchad, señor don Marcos» (fols. 64r-66r).

Romance $[\mathrm{X}]$. «Dura ley al pensamiento» (fols. 67r-70v).

Canción. "Pulsen las musas las hiladas venas», en nueve estrofas sexta rima en versos endecasílabos y heptasílabos, excepto las tres últimas en que los versos son endecasílabos (fols. 21r-22r).

El volumen está precedido por una portada sencilla que recoge el título, la dedicatoria a doña Mariana de Borja y Cerceda, junto con el lugar y fecha en que se compiló, Madrid en el año 1715. Esta breve información se enmarca con un triple recuadro trazado a mano y que ocupa casi la totalidad del espacio de la página. Las composiciones poéticas con métrica culta y popular se entremezclan en este tomo, sin que pueda suponerse un orden subyacente, aunque es destacable que los sonetos y los romances son los escritos más comunes, cada uno representante destacado de una forma de hacer poesía concreta.

En las primeras hojas se sitúan varios sonetos, y el examen atento de la disposición de las mismas y de la obra que cada una de ellas aloja, nos remite a esa característica de ejemplar facticio. El primer soneto, por ejemplo, viene acompañado del número XIII, al que se ha tachado las tres primeras cifras, resultando ser el «Soneto I». El mismo proceso se lleva a cabo con el siguiente poema que pasa de ser el XII al II. Sin embargo, encontramos otra forma de numeración en el tercero de ellos, donde se tacha «De Don Francisco Bances Candamo», información no necesaria al encontrarse en un tomo a su nombre, y en el espacio que resta entre esta atribución y el primer verso del poema, se inserta la denominación "Soneto 3», en este caso en cifras arábigas. Así, se puede deducir que la elección de los caracteres romanos en los dos primeros casos viene dada por la clasificación previa que se había dado a estos textos, aunque no sepamos de dónde proceden. Probablemente se tratase 
de papeles sueltos que puso en orden el propio autor y que él tendría guardados o que copió de nuevo para poder conservarlos. De este modo, volviendo a los dos primeros sonetos, llama la atención que están escritos en el recto de la hoja y ocupan la totalidad del espacio. También, para destacar un detalle del estilo escritor o copista de Bances Candamo, es posible referir que utiliza la sangría francesa en los primeros versos de cada cuarteto y terceto, característica tipográfica que se mantiene a lo largo de todo el autógrafo. A continuación, se muestra un ejemplo que recoge todas estas particularidades.

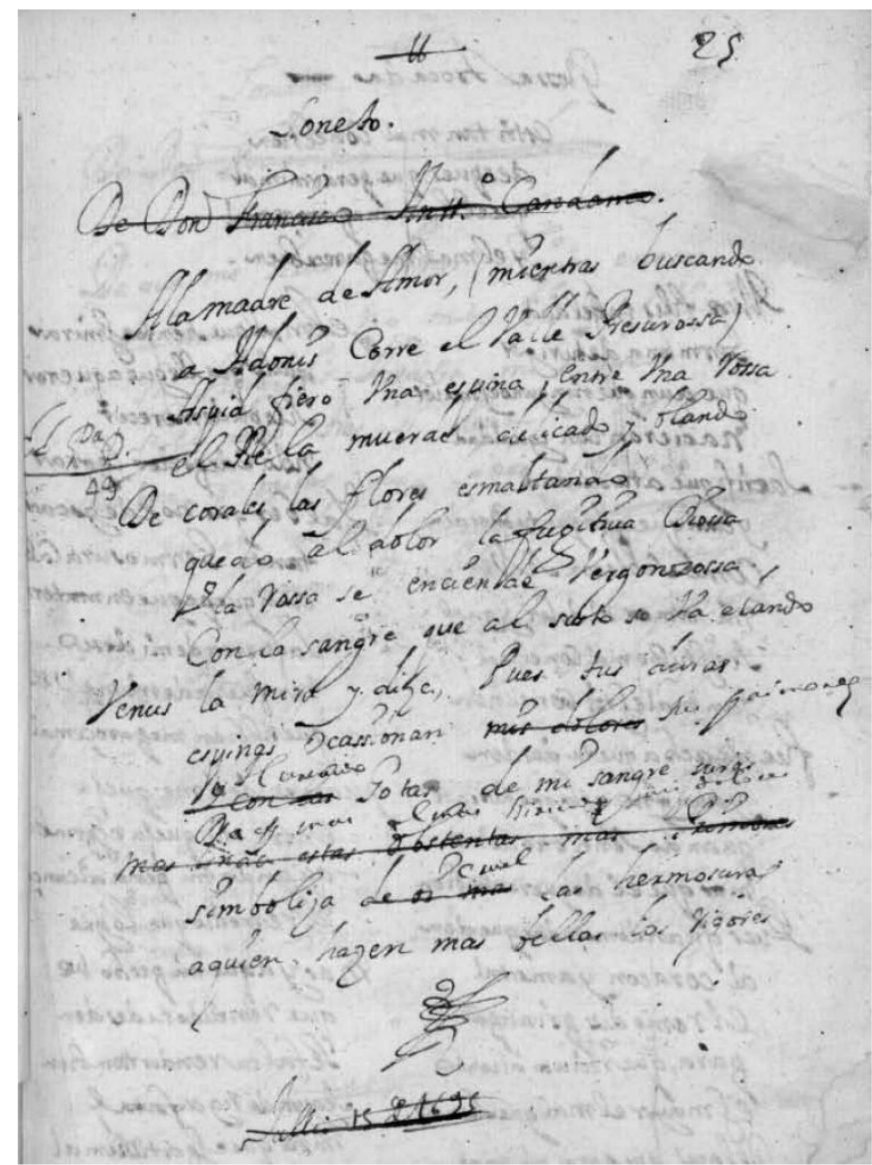

Figura 1. Fol. $25 r^{5}$

${ }^{5}$ Solo reproduzco aquí algunos fragmentos, pues el manuscrito autógrafo puede encontrarse en la Biblioteca Digital Hispánica (Bances Candamos, 1715). 
Del mismo modo que tacha la información no necesaria, como su nombre en el «Soneto 3» (fol. 3r), así actúa en el «Soneto 6» (fol. 12v) o «Soneto» (sin numeración, Figura 1, fol. 25r, con otro ejemplo en fol. 26r), entre otros. Además, en el caso de estos dos últimos, y del romance de los fols. 29r-32r ${ }^{6}$, elimina la fecha que originalmente aparece al final, 1695 en los sonetos, 1699 en el romance (sin título ni numeración).

Hasta el momento, son dos los aspectos más sobresalientes que podemos destacar de este tomo "artificial»: toda vez que aparecen datos sobre fecha de escritura y autoría estos se eliminan, para proporcionarle un sentido global a la obra y prescindir de información ya conocida. No obstante, su pervivencia en la página escrita nos muestra que son documentos antes escritos y ahora reunidos para la presente propuesta editorial, excepto un romance que examinaremos más tarde. Y también, que no se ordenan de una forma sistemática ni mantenida a lo largo del tomo, pues si al principio se reelabora la numeración original, luego se añade una nueva, pero también aparecen abundantes casos de poemas sin cifra ni título. Junto con el uso aleatorio de cifras romanas y arábigas, encontramos mezcolanza en el tipo de letra utilizado: en los dos primeros sonetos del tomo (I y II, procedentes de XIII y XII respectivamente), se utiliza una letra cursiva elaborada (fols. 1r y 2r); en el «Soneto 3» (fol. 3r, la cursiva es más sencilla y el número romano se cambia por arábigo); la carta-ovillejo no tiene siquiera título (fols. 13r-16v); el término «canción» se escribe en versalita (fol. 21r), etc. por citar solo algunas peculiaridades sobre esta materia.

Respecto a la disposición de los textos en los folios, como antes hemos mencionado, existen casos en los que el soneto ocupa todo el espacio, dando como resultado una apariencia limpia y cuidada. Por el contrario, según avanzamos en el volumen, se percibe la acumulación de amplias partes en blanco e incluso hojas completas sin utilizar. Esta singularidad se produce cuando, por ejemplo, Bances Candamo quiere incluir más de un soneto por folio: los versos no caben en una sola cara y pasan a la siguiente, aunque apenas ocupan unas pocas líneas. El autor, consciente de esta falta de texto y de la posibilidad de insertarlo más tarde, traza una serie de puntos que destacan las líneas disponibles para la incorporación

\footnotetext{
${ }^{6}$ Precisamente en este lugar se produce un salto en la paginación, el folio que sigue al 32 es el 40.
} 
de más versos. Por el contrario, quizá la redacción de las Obras autógrafas fue apresurada o poco cuidada (o incluso ambas circunstancias al mismo tiempo), y estas marcas autoriales permanecen a la vista del lector tres siglos después, como podemos comprobar en el siguiente extracto del autógrafo en el que se destaca este procedimiento concreto (Figura 2).

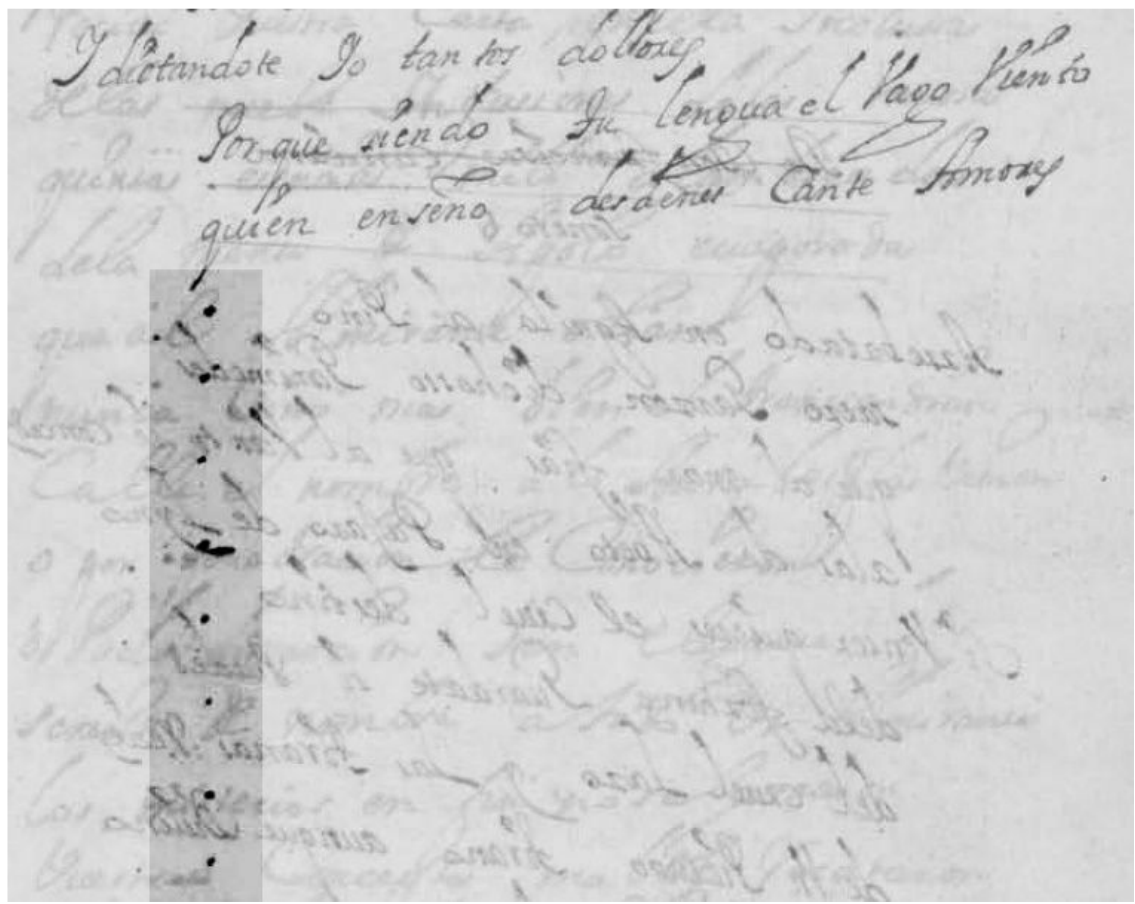

Figura 2. Fol. 4r

En contraposición con esta holgura de espacio, la glosa trocada que se copia en el fol. $25 \mathrm{v}$ se presenta a doble columna a excepción de los primeros cuatro versos, aunque este es el único caso en el manuscrito de un aprovechamiento de la página tan exhaustivo.

\section{TEXTOS EN EL AUTÓGRAFO}

Según hemos podido comprobar a partir de la lista de Oteiza (2017), la gran mayoría de los textos copiados por Bances Candamo en el ms. 2248 son comunes con la edición de las Obras líricas publicada en Madrid en el 1720 a cargo Nicolás Rodríguez y modernamente editada por 
Fernando Gutiérrez (Bances Candamo, 1949) ${ }^{7}$. Estos títulos se pueden comprobar en el inventario recogido con anterioridad. A esta investigación hay que sumar la elaborada por Cuervo-Arango (1916: 55-57), en la que da noticia de algunas líneas inéditas contenidas en el autógrafo y no recogidas en ningún impreso ni edición. En concreto, se trata de tres composiciones de diversa extensión, temática y métrica: una glosa trocada, una letrilla y un epigrama. Pero, asimismo, dentro de las Obras se esconden algunos fragmentos de textos inconclusos o descartados que son fácilmente legibles porque apenas están tachados con una línea vertical. Aquellas composiciones ya mencionadas por Cuervo-Arango (1916) se señalan, así como también las que solo se encuentran en el manuscrito: fragmentos de un romance y su título (fol. 61v, descrito por CuervoArango, 1916: 57 como "de declaración no muy correcta»; es de condición burlesca y está dirigido a la dama Anarda) y un lance (fol. 16v). Esta pieza parece que está concluida porque se enmarca el texto por debajo con líneas discontinuas, pero al titularlo en plural «Lances» es factible suponer que podría tener la intención de escribir más de uno. Sin embargo, al presentarse al final de una página, no hay un espacio en blanco que pueda corroborar esta hipótesis ni está seguido otro texto de las mismas características. Cuervo-Arango no menciona esta composición poética en su estudio.

En este cuadro se incluyen tanto los poemas o títulos mencionados por Cuervo-Arango (1916: 55-57) como los que no, con la intención de

${ }^{7}$ Todas las piezas insertas en las Obras autógrafas están en Obras líricas (1720), que añade, además, otras tantas de variado carácter y extensión: «Descripción y viaje de Tajo. Idilio» (fols. 5-28); «Al primer ministro. Romance II» (fols. 63-85); «Soneto XII» (fol. 86); «En la muerte del Venerable Padre Maestro Fray Raimundo Lumbier. Romance VI» (fols. 118-121); «Respuesta al Ilustrísimo señor Don Tomás Jiménez Pantoja, Conde de la Estrella, del Consejo Real, siendo Presidente de Hacienda. Romance» (fols. 129-151); «Soneto XXII» (fol. 152); «Habiendo llegado a la Corte cantidad de poetas cultos, le escribió este a un amigo. Soneto XXII» (fol. 129; error a partir de aquí, salta del fol. 152 a 129); «Respuesta. Soneto XXIII» (fol. 130); «El gran César africano. Guerra púnica española. Poema épicode la conquista de Túnez por el emperador rey de España Don Carlos» (fols. 131-212); «En alabanza del discurso que escribió para forma una librería selecta al Excelentísimo Señor Don Antonio Martín, Duque de Alba, año de 1691. Soneto XXIV» (fols. 272-273); «Soneto XXV» (fol. 213); «Romance VIII» (fols. 216-222); «Endechas endecasílabas» (fols. 222-224); «Fiesta de toros» (fol. 229).

${ }^{8}$ Según lo define el $D R A E$ : «En el poema dramático, o en cualquier otro análogo, y en la novela, suceso, acontecimiento, situación interesante o notable». 
ofrecer el panorama completo (aunque inacabado o suprimido) de la poesía que Bances Candamo incorpora en sus Obras.

\begin{tabular}{|c|}
\hline $\begin{array}{c}\text { REDONDILLA } \\
\text { A ciertos papeles de comedia que mandaron sacar disculpando su letra. } \\
\text { De un amigo del escritor }\end{array}$ \\
\hline $\begin{array}{l}\text { Yo no sé escribir más bien } \\
\text { pues esto fue en conclusión } \\
\text { de lo que me dio lección } \\
\text { mi maestro Mendigurén. } \\
\text { (Cuervo-Arango, 1916: } 55 \text {; ms. fol. } 24 \mathrm{v} \text {, aunque Cuervo-Arango ubica } \\
\text { esta pieza en fol. 25v, que, sin embargo, está ocupado en su totalidad } \\
\text { por la glosa trocada) }\end{array}$ \\
\hline EPIGRAMA \\
\hline $\begin{array}{l}\text { Imposibles es que te duelas } \\
\text { mi celid de tu fortuna } \\
\text { pues no teniendo ninguna } \\
\text { dices te duelen las muelas. } \\
\text { Yo no lo creeré en mis días } \\
\text { pues todas postizas son } \\
\text { repara con atención } \\
\text { si son las muelas o encías. } \\
\text { (Cuervo-Arango, 1916: 57; ms. fol. 28v) }\end{array}$ \\
\hline $\begin{array}{l}\text { LETRILLA } \\
\begin{array}{l}\text { Escarmentado de los asaltos de la hermosura, lo deja todo. De un amigo } \\
\text { del escritor }\end{array} \\
\text { (Cuervo-Arango, 1916: } 55 ; \mathrm{ms} \text {. fol. } 48 \mathrm{v} \text { ) }\end{array}$ \\
\hline $\begin{array}{l}\text { Hermos } \\
\text { (Ms. fol. 48v; Cuervo-Arango no menciona este inicio del primer verso de } \\
\text { la letrilla que debía empezar en el folio siguiente) }\end{array}$ \\
\hline
\end{tabular}




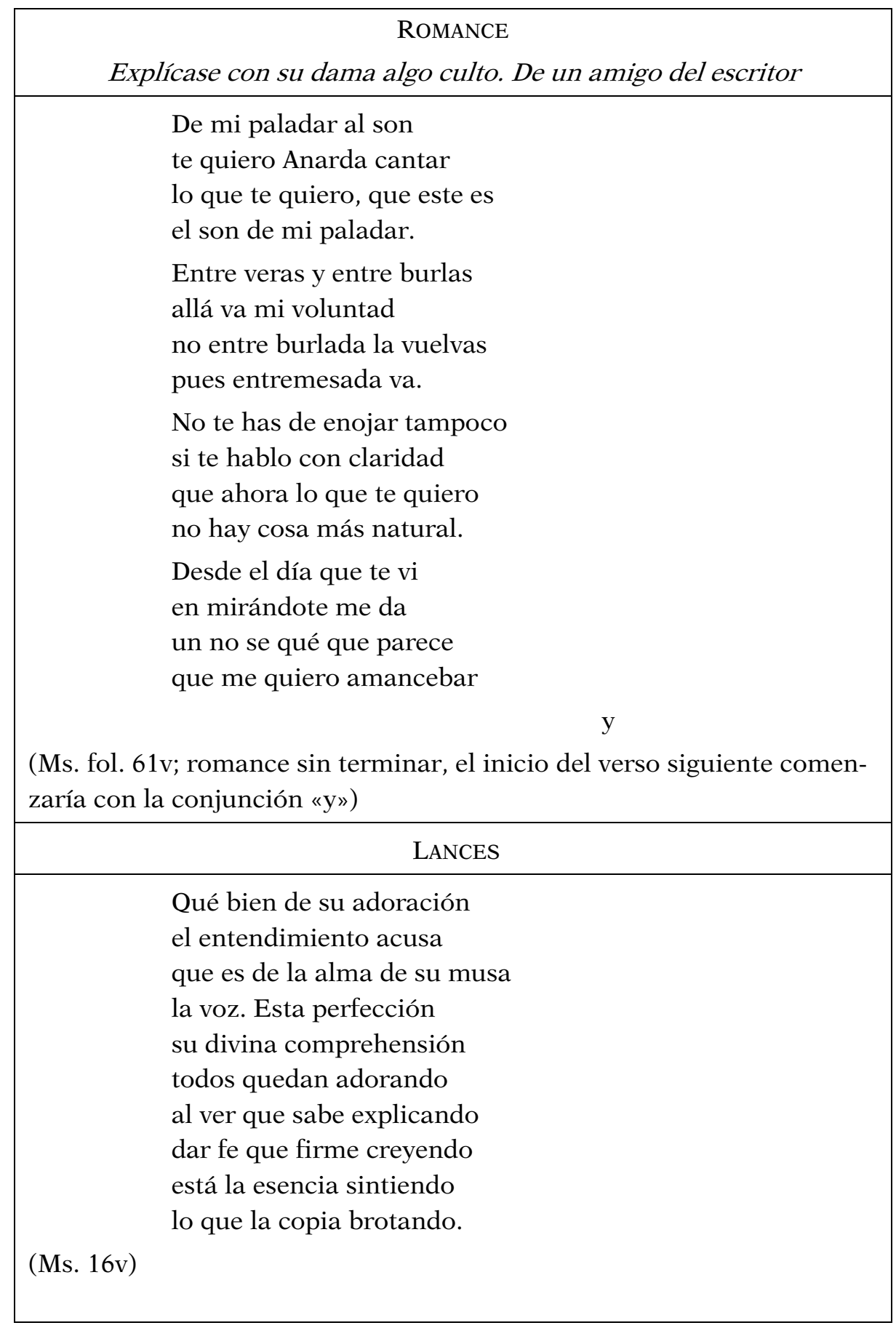




\begin{tabular}{|c|}
\hline GLOSA TROCADA \\
\hline $\begin{array}{l}\text { Estoy tan mal con el bien } \\
\text { después que perdí mi mal } \\
\text { que el bien me parece mal } \\
\text { y el mal me parece bien. } \\
\text { Miré Filis tu beldad } \\
\text { hermana de tu rigor, } \\
\text { que aunque ninguno es mayor } \\
\text { nacieron con igualdad. } \\
\text { Sacrifiqué a tu deidad, } \\
\text { y aunque aplaqué tu desdén, } \\
\text { como se vieron se ven } \\
\text { mi amor al dolor igual. } \\
\text { Si estuve mal con el mal } \\
\text { tan mal estoy con el bien. } \\
\text { Fue mi achaque tu desdén, } \\
\text { y aunque no aplaqué tu rigor, } \\
\text { cuando sentí otro dolor } \\
\text { más que el de quererte bien. } \\
\text { Pues cuando mandas que den } \\
\text { al corazón ya mortal } \\
\text { el remedio principal } \\
\text { para que reciba aliento, } \\
\text { es mayor el mal que siento } \\
\text { después que perdí mi mal. } \\
\text { El mal que siento es mirar } \\
\text { que lo que llegué a querer } \\
\text { si lo pude merecer } \\
\text { no lo he de poder lograr. } \\
\text { Y al ver que no he de gozar } \\
\text { tanta hermosura cabal } \\
\text { aunque pequé en material } \\
\text { la fuerza de mi deseo } \\
\text { tuera de mí me veo } \\
\text { quen me parece mal. }\end{array}$ \\
\hline
\end{tabular}




\begin{tabular}{|l|}
\hline Cuando de ti me quejé \\
entre mi queja esperaba \\
cuando mi pena alcanzaba \\
el remedio que logré. \\
Mas ya que mi pecho ve \\
que rendido tu desdén \\
le falta rendir también \\
segundo rigor fatal \\
miro que es por ti mi mal \\
y el mal me parece bien. \\
(Cuervo-Arango, 1916: 55-56; ms. fol. 25v)
\end{tabular}

Además, de entre los textos tachados por el autor, es posible destacar dos que cobran especial relevancia al mostrar fases de una primera composición poética que será reelaborada y reescrita después. Afortunadamente, las muestras de ello también aparecen en este volumen de Obras. En concreto, hablamos del «Romance heroico 3» (fol. 46v) y del «Soneto 19». Al águila que llevaba los rayos a Júpiter» (fol. 27v). En el caso del «Romance heroico 3», comienza Bances Candamo escribiendo las dos primeras estrofas en la mitad inferior del fol. 47v, mas no le queda espacio, y en el 48r tiene ya una página sobrecargada con los versos de dos sonetos. La solución que encuentra es tachar lo ya compuesto del romance heroico y trasladarlo al fol. 49r. Esa carilla, de nuevo, en su segunda parte está en blanco y también la que sigue, la 49v. En el autógrafo se aprecia el pegado de fragmentos de hojas blancas con la intención de anular definitivamente el texto que había debajo. A pesar de este remedio editorial, los espacios conseguidos no se utilizan, sino que el romance heroico se retoma en el fol. 50r tras una carilla y media sin escritura.

De esta suerte, es posible destacar cuatro fases o estadios en la composición de las piezas que se incluyen en las Obras autógrafas de Bances Candamo: textos y folios sin apenas errores de copia ni correcciones (in itinere o a posteriori) que podrían entenderse como copias en limpio definitivas de escritos anteriores, situación que describe principalmente el caso de los romances. Otras carillas con multitud de correcciones y tachados, afectando incluso a la reelaboración y reescritura de versos, 
característica de aquellas donde se localizan los sonetos (es posible recordar que estas formas estróficas precisan de una gran pericia y dominio de la métrica, por lo que su escritura es más compleja). Un ejemplo de escrito del cual se conservan dos versiones: la desechada y la "oficial», el «Soneto III» o «Al águila que llevaba los rayos a Júpiter». Estas tres muestras nos confirman que las Obras es un volumen de esencia facticia, que aúna los originales que Bances Candamo conservaba de sus poemas. En algunos casos eran copias limpias, si bien en otros no tuvo tiempo de brindar una disposición más pulcra. Además, probablemente sin pretenderlo, nos hace partícipes de la reelaboración y reescritura de un soneto, aspecto esencial para poder comprender mejor el proceso de escritura de un autor. Por último, encontramos el pasaje relativo al «Romance heroico 3», ya mencionado, que por la situación textual que ofrece, estaría copiado una vez confeccionado el tomo de las Obras. Así se explica el aprovechamiento que Bances Candamo efectúa sobre algunas páginas que habían permanecido en blanco.

Uno de los aspectos sobre los que conviene profundizar es la reelaboración del soneto «Al águila que llevaba los rayos a Júpiter», que podemos considerar inédito. Tras una lectura minuciosa, comprobamos que se trata de una versión descartada del «Soneto 3 » del fol. 3r. Ambos poemas se copian aquí destacando las disparidades entre ellos, que van desde el título (más detallado en la primera versión) hasta algunos versos completos o cambios que solo afectan a palabras concretas. Según veíamos en la utilización de la glosa trocada y como confirma Arellano (1991), Bances Candamo era un poeta de corriente culterana y gran admiración por Góngora ${ }^{9}$. De ahí que el siguiente texto invoque al lector importantes reminiscencias del soneto «A Júpiter» del poeta cordobés.

${ }^{9}$ Este aspecto también es corroborado por Oteiza (2017: 449): «Los metros cultos (silva y sexta rima) son la forma de los poemas más culteranos en los que la influencia e imitación de Góngora es extrema». En estos metros cultos se integra asimismo el soneto. 


\begin{tabular}{|c|c|}
\hline SONETO III & $\begin{array}{l}\text { AL ÁGUILA QUE LLEVABA LOS } \\
\text { RAYOS A JÚPITER }\end{array}$ \\
\hline $\begin{array}{l}\text { De la cumbre del Etna monumento } \\
\text { de encelado, oficina de Vulcano, } \\
\text { el ministro de Júpiter grifano } \\
\text { vuela al cielo, taladra el firmamento. } \\
\text { Donde llevas el rayo que violento } \\
\text { su garra vibra con rigor tirano, } \\
\text { rayos llevas al cielo, siendo ufano } \\
\text { bajel de fuego que navega el viento. } \\
\text { ¿Por qué, decid, labrasteis con desvelo } \\
\text { (Cícoples) del abismo en la oficina } \\
\text { armas a Jove, extraños de recelo? } \\
\text { Si arruinarnos con ellas determina, } \\
\text { no os quejéis si forjamos en el suelo } \\
\text { los rayos con que el cielo nos fulmina. } \\
\text { (Ms. fol. 3r, incluido en Bances } \\
\text { Candamo, 1949: 62-63) }\end{array}$ & $\begin{array}{l}\text { De la cumbre del Etna (monumento } \\
\text { de encelado, si fragua de Vulcano) } \\
\text { vuela una águila, y juzgo que en su mano } \\
\text { una estrella conduce al firmamento. } \\
\text { Pero (jay!) no es sino un rayo que violento } \\
\text { vibra su garra con rigor tirano: } \\
\text { un rayo lleva al cielo siendo ufano } \\
\text { bajel de fuego que navega el viento. } \\
\text { ¿Por qué, decid, labrasteis con desvelo } \\
\text { (Cícople) del abismo en la oficina } \\
\text { a Júpiter las armas, si su anhelo } \\
\text { arruinarnos con ellas determina? } \\
\text { No os quejéis pues forjamos en el suelo } \\
\text { los rayos con que el cielo nos fulmina. } \\
\text { (solo en Ms. 2248, fol. 27v) }\end{array}$ \\
\hline
\end{tabular}

\begin{tabular}{|l|}
\hline \multicolumn{1}{|c|}{ A JÚPITER (GÓNGORA) } \\
\hline Tonante monseñor, ¿de cuándo acá \\
fulminas jovenetos? Yo no sé \\
cuánta pluma ensillaste para el que \\
sirviéndote la copa aún hoy está. \\
El garzón frigio, a quien de bello da \\
tanto la antigüedad, besara el pie \\
al que mucho de España esplendor fue, \\
y poca, mas fatal, ceniza es ya.
\end{tabular}




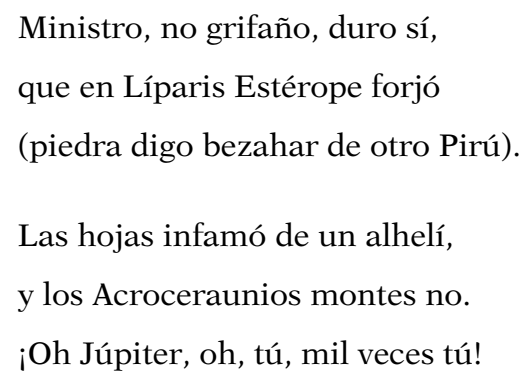

Si la inclinación estética está clara y es recurrente, lo mismo sucede con la temática elegida por el autor en sus textos más elaborados; así lo asevera García Castañón (1990: 712-713), quien también aborda la heterogeneidad de la poesía del asturiano:

La mayor parte de los sonetos de Bances son de temática amorosa. Destaca la ausencia de sonetos de tipo moral o metafísico, tal vez porque sus escasos años y la frivolidad de la vida cortesana no eran las circunstancias más adecuadas para el tema [...] No obstante, el tratamiento del tema difiere de los cancioneros amorosos de corte petrarquista: no hay en el poemario de Bances Candamo un hilo conductor que dé uniformidad al conjunto, falta uniformidad globalizadora, incluso en la propia disposición tipográfica de los poemas.

Pasemos ahora a examinar las correcciones e intervenciones de Bances Candamo en su manuscrito autógrafo.

\section{INTERVENCIONES AUTORIALES}

Siguiendo los conceptos teóricos propuestos por Kroll (2017: 137) en su taxonomía, mediante la cual cataloga las correcciones autoriales de Calderón de la Barca en sus comedias autógrafas, las intervenciones de Bances Candamo en sus Obras aparecen en los tres momentos de la escritura: inventio, dispositio y elocutio.

En el primer caso, la inventio, que puede afectar al título, al tema, a los personajes o al espacio/tiempo dramático (Kroll, 2017: 137), se encuentra en el ya mencionado «Soneto III», anteriormente titulado de un modo más extenso «Al águila que llevaba los rayos a Júpiter», aunque 
más que hablar de una corrección, sería una supresión debida a la dinámica editorial del resto de poemas del volumen que, en su gran mayoría, carecen de título y solo van numerados, en especial aquellos que son más cuantiosos como los romances y los sonetos.

En relación con las correcciones que se encuentran en la dispositio, Kroll (2017: 137) las subdivide en cuatro tipos: eliminación, permutación, añadido y sustitución. A continuación, vamos a examinar el «Soneto 15» (fol. 47v), un texto que presenta intervenciones autoriales de diversa índole (figura 3).

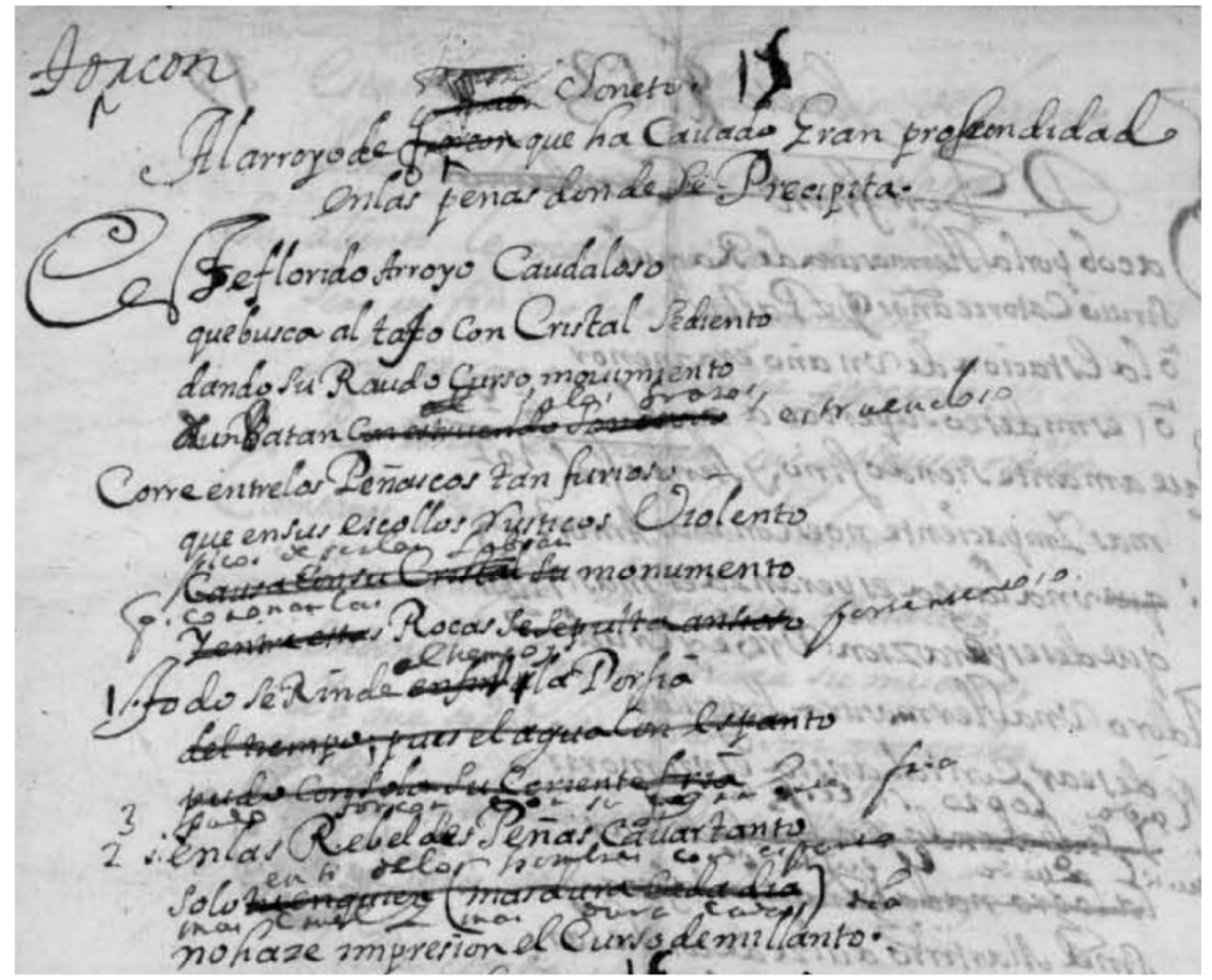

Figura 3. Fol. 47v 


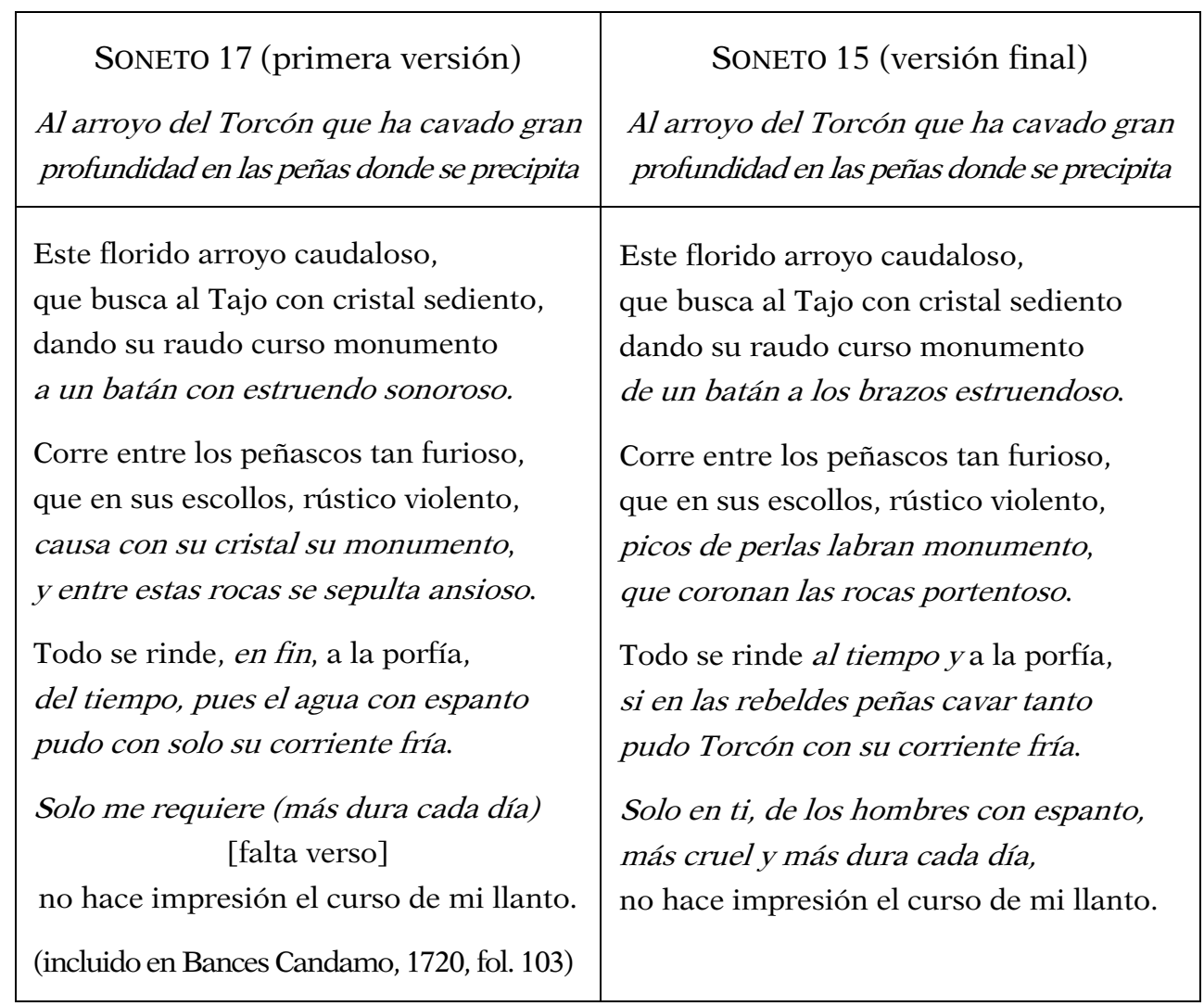

En primer lugar, localizamos una corrección en la numeración del soneto que pasaría de ser el 17 al 15, según se comprueba en el original, ya que se ha sobrescrito una cifra encima de la otra. Además, es uno de los sonetos que se ofrece acompañado de título «Al arroyo de Torcón ${ }^{10}$, que ha cavado gran profundidad en las peñas donde se precipita», un paratexto donde Bances Candamo corrige hasta tres veces la opción de «Torcón» para, finalmente, establecerla como la lectura definitiva en un apunte situado en la parte superior izquierda. Puede pensarse que la corrección se realiza durante una revisión posterior a la escritura, porque de haber sido in itenere podría estar ocupando el espacio interlineal entre las dos partes en que se divide el título.

Una vez ya en el texto del soneto, visualmente se aprecia cómo, mientras en el primer cuarteto la escritura y copia es limpia y sin apenas

${ }^{10}$ Afluente del Tajo, nace en los montes de Toledo. 
errores, las faltas se van acumulando hasta llegar a su apogeo en el último terceto. Bances Candamo reelabora casi totalmente algunos versos, según podemos percibir: así el tercero del segundo cuarteto pasa de ser "causa contra su cristal su monumento» a "picos de perlas labran monumento». La sustitución responde a una pura cuestión de estilo, pues ni la rima ni el cómputo silábico se ven afectados. Esta razón será la que motive la mayoría de revisiones en este soneto a excepción de la más breve, la del primer verso del primer terceto, donde se tacha «en fin a» para escribir «el tiempo». Estas intervenciones autoriales, igual que la del título, se situarían en un momento posterior a la escritura del mismo, lo que puede comprobarse tanto por la ubicación de las segundas (o terceras) lecturas en la página como por la caligrafía del autor, menos elaborada y más deslavazada.

Respecto a la dispositio, las correcciones y sustituciones son tan frecuentes en el segundo cuarteto y el primer terceto, que, en este último ejemplo, el autor se apoya en la numeración de los versos para fijar la disposición que correspondería. Al primer verso del primer terceto le siguen dos líneas tachadas, tras las cuales se añaden otros dos versos. Pero no es esta la lectura definitiva, sino que después el tercer verso se raya, se corrige y se añade el número tres al que antecederá el verso escrito a continuación en el autógrafo, que, mediante la indicación de dos, pasaría a precederlo en el texto final ideado por el poeta.

Este procedimiento de reordenación se muestra inmediatamente después en el autógrafo, en el fol. 48r (figura 4), que recoge algo más de la mitad de un romance. La disposición inicial de los octosílabos, que Bances Candamo ofrece agrupados en tandas de cuatro versos con sangría francesa, se modifica tal como vemos en el siguiente extracto del manuscrito. Un aspecto curioso es que esta nueva colocación termina en este folio y no se mantiene en el resto del romance copiado en el vuelto, quizá porque el poeta estuviera satisfecho con el final de su composición o por la premura con que se realizó la revisión. 


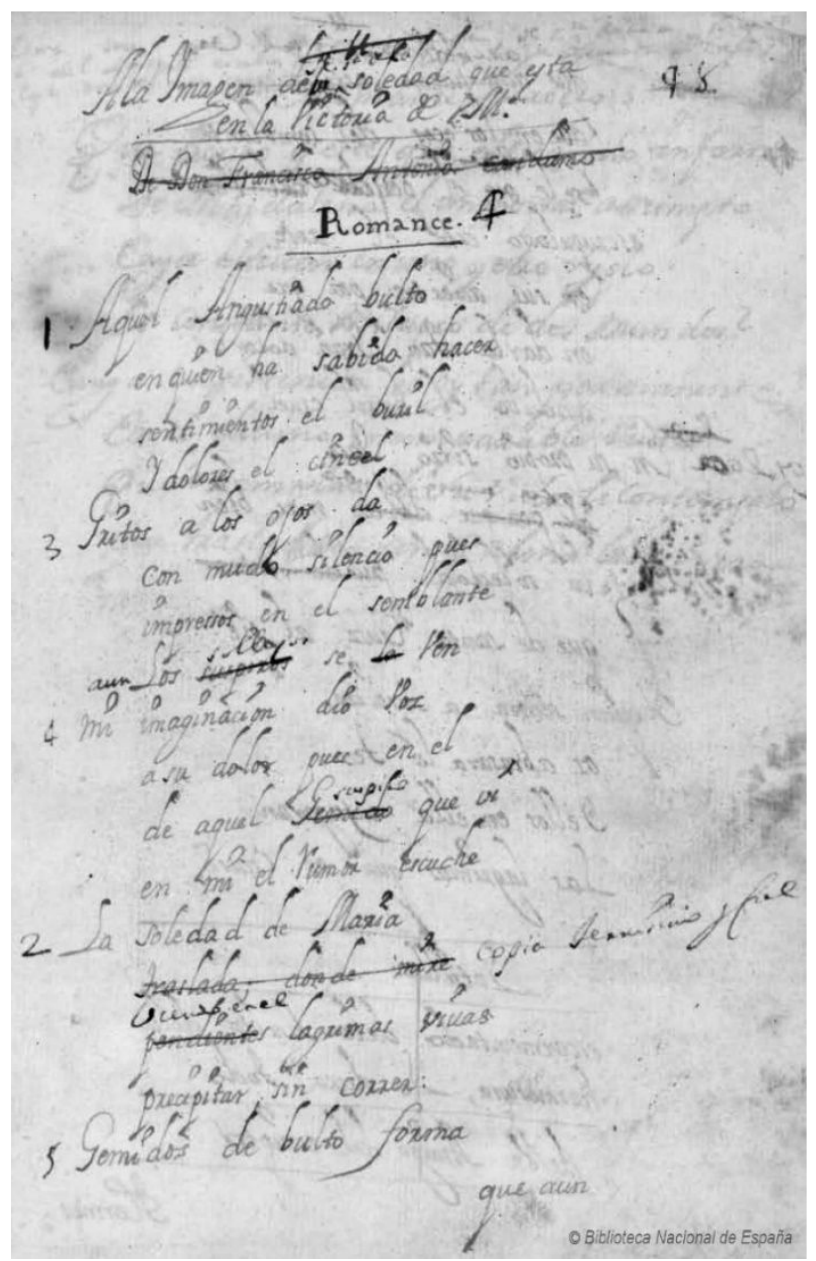

Figura 4. Fol. 48r

Por último, existen las revisiones que afectan a lo que Kroll denomina elocutio y que divide en actuaciones del autor relacionadas con la puritas poética, la compositio, el ornatus y la métrica. Como ejemplos de esta lectura que hace el poeta con el fin de incluir en sus obras los conceptos y la métrica precisa, encontramos un verso completo sustituido «traslada donde mire» por «copia tiernísimo y fiel» y también palabras sueltas: «suspiros» por «sollozos» o «gemido» por «suspiro». Al haber eliminado en primer lugar «suspiros», versos más tarde es un término disponible que no se ha repetido anteriormente. En último lugar, y como epítome de estas enmiendas breves pero esenciales, está la silva del fol. 62r, donde 
Bances Candamo, que ya parece conocer y manejar las reglas de la ortografía actual, revisa y sustituye aquellos casos en que aparece la letra «b» donde tendría que ser «V»: así en «Silba» por «Silva», «biento» por «viento» o «berde» por «verde». El autor muestra una conciencia ortográfica que ya se conocería en la época, aunque no se fijase hasta la publicación de la Ortographía española a cargo de la Real Academia Española en 1741. Se pueden apreciar varias de estas intervenciones (figura 5), colocadas a posteriori tras la composición del poema, pues la tinta es claramente más oscura.

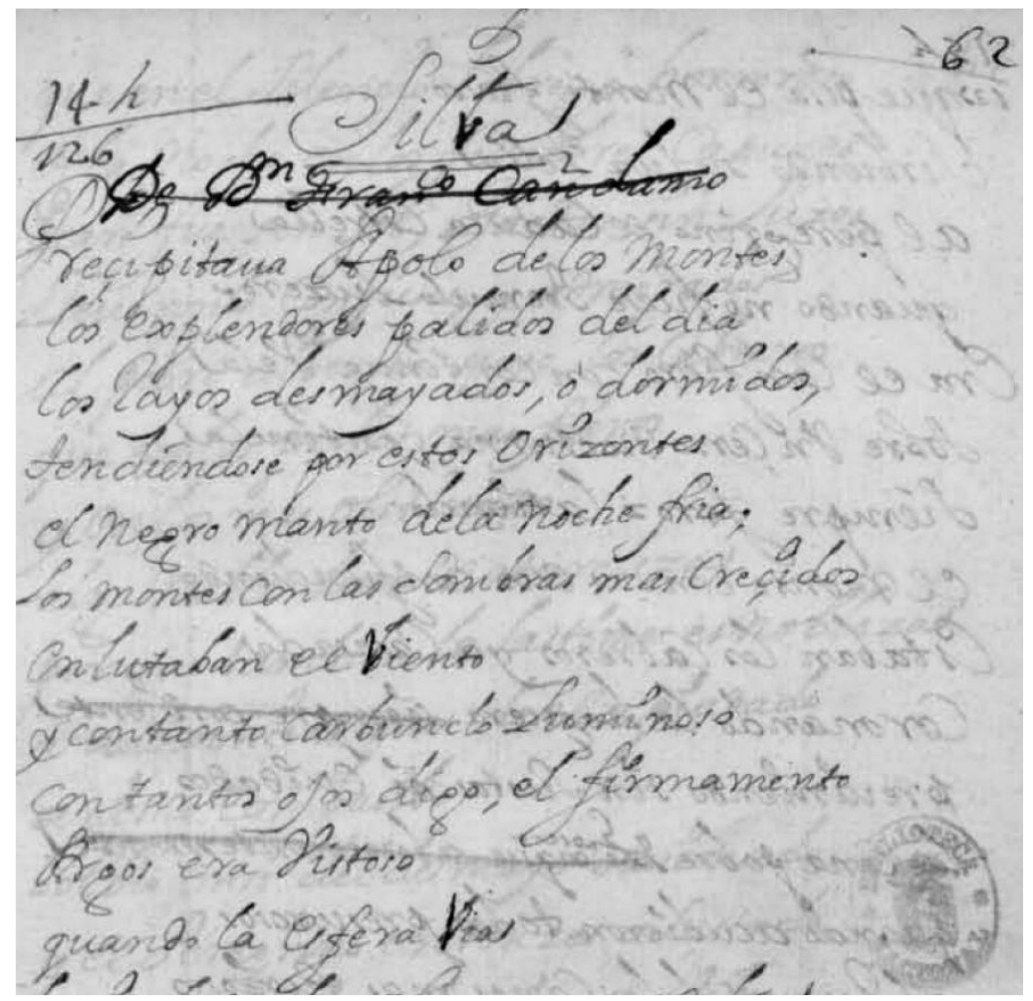

Figura 5. Fol. 62r

\section{CONCLUSIONES}

A lo largo de estas páginas hemos examinado con atención parte del corpus autógrafo de Bances Candamo, en concreto, las poesías contenidas en las Obras, manuscrito 2248 de la BNE. El objetivo principal 
era estudiar el aspecto externo, la disposición interna de las composiciones poéticas y las intervenciones que el autor realizó en los textos aquí recogidos con la intención de acercarnos al proceder durante la escritura y el proceso editorial del autor en la construcción de este volumen facticio. Ahora es posible confirmar que este análisis ha ofrecido luz e importantes datos sobre las Obras: los poemas que recoge no fueron escritos a propósito para este tomo, sino que proceden de diversos orígenes, siendo algunos textos copias en limpio, pero otros, en cambio, reflejan el intenso proceso de escritura realizado por Bances Candamo.

También, contamos en este documento con dos versiones de un soneto, la primera de ellas inédita y esencial para comprobar cómo los textos, poéticos en este caso, estaban sometidos a un proceso de evolución. Existen diversas fases en la redacción de los versos: este aspecto puede percibirse en las correcciones realizadas a un soneto (como es el caso) o a las variantes del mismo en dos composiciones diferentes. Asimismo, la labor del poeta continuaba una vez fijado el contenido, que después pulía para lograr una mayor belleza, precisión léxica o rigor métrico. Estas cuestiones también han sido examinadas en el autógrafo de Bances y nos han aportado datos muy interesantes, sobre su oficio poético y también sobre una temprana conciencia ortográfica.

De este modo, podemos concluir afirmando que los autógrafos muchas veces nos ofrecen un material inigualable para acercarnos a las intenciones editoriales, el proceso de composición y la corrección de un creador literario, como, espero, se haya podido demostrar ahora con las Obras del insigne autor asturiano.

\section{BIBLIOGRAFÍA CITADA}

ARELlano, I. (1987): «"El entremés de las visiones” de Bances Candamo». Criticón, 37, 11-35.

ARELlaNo, I. (1988): «Bances Candamo, poeta áulico. Teoría y práctica en el teatro cortesano del postrer Siglo de Oro». Iberoromania, 27-28, 42-60.

ARELlano, I. (1991): «Presencia de Góngora en Bances Candamo, poeta oficial de Carlos II». Revista de Literatura, 106, 619-630.

ARELlano, I. (2015): «Calderón en su taller. Algunas intervenciones en los autógrafos de los autos sacramentales». Anuario calderoniano, 8, 31-52. 
Bances Candamo, F. A. (1715): Obras de don Francisco de Bances Candamo dedicadas a la excelentísima señora doña Mariana de Borja y Cerceda. Madrid (ms. BNE 2248, en línea: <http://bdh-rd.bne.es/viewer.vm?id=0000089500\& page $=1>$, consulta: 15 de agosto de 2020).

Bances Candamo, F. A. (1720): Obras lyricas. Ed. N. Rodríguez Francos. Madrid: Julián del Río Marín.

Bances Candamo, F. A. (1949): Obras líricas. Ed. F. Gutiérrez. Barcelona: Selecciones Bibliófilas.

Bances Candamo, F. A. (2004): Poesía selecta. Ed. S. García Castañón. Gijón: Libros del Pexe.

CheCA Beltrán, J. (2012): «Bances Candamo, Luzán y el Neoclasicismo». Edad de Oro, 31, 111-128.

CRIVELlaRI, D. (2013): Marcas autoriales de segmentación en las comedias autógrafas de Lope de Vega. Estudio y análisis. Kassel: Reichenberger.

CRIVELLARI, D. (2018): «Métrica y marcas de segmentación en los autos sacramentales autógrafos de Lope». ARTENUEVO. Revista de Estudios Áureos, 5, $165-188$.

Cuervo-Arango, F. (1916): Francisco Antonio de Bances y López Candamo. Estudio bio-bibliográfico y crítico. Madrid: Impr. de los hijos de M.G. Hernández.

Del Río Marín, J. (1949): «Vida y escritos de Bances Candamo». En F. A. Bances Candamo, Obras líricas. Ed. F. Gutiérrez. Barcelona: Selecciones Bibliófilas, págs. 23-34.

DuARTE, J. E. (en prensa): «El César africano, poema épico de Bances Candamo».

DUARTE, J. E. et al. (2010): Bibliografía general del teatro de Bances Candamo. Pamplona: GRISO-Universidad de Navarra (en línea: <https.//hdl.handle.net/ 10171/47455>, consulta: 20 de agosto de 2020).

EchaVARREN, A. (2013): «Un poema desconocido de Francisco Bances Candamo con nuevos aportes biográficos». Iberoromania, 78, 178-203.

ESCUDERO BAZTÁN, J. M. (2020): «El magisterio de la escritura calderoniana en sus autos sacramentales autógrafos». En Mata Induráin, C. (coord.): «A dos luces, a dos visos». Calderón y el género sacramental en el Siglo de Oro. Kassel: Reichenberger, 19-39.

GARCía CASTAÑÓN, S. (1990): "Algunas consideraciones sobre la poesía de Bances Candamo». Boletín del Instituto de Estudios Asturianos, 136, 707-715. 
HERnANDO Morata, I. (2015): «Marcas autoriales en los manuscritos autógrafos de Calderón». Criticón, 124, 185-202.

KROLL, S. (2017): Las comedias autógrafas de Calderón de la Barca y su proceso de escritura. Frankfurt: Peter Lang.

MoIR, D. W. (ed.) (1970): Francisco A. Bances Candamo, Teatro de los teatros de los pasados y presentes siglos. London: Tamesis.

OTEIzA, B. (2017): «Bases para la edición crítica de la poesía exenta del dramaturgo Bances Candamo». Hipogrifo, 5.2, 443-460.

OTEIZA, B. (2020): «Vida, autoridad, desengaño y burla en la poesía de Bances Candamo». Hipogrifo, 8.1, 75-93.

RODRÍGUEZ ORTEGA, D. (2020): «El manuscrito autógrafo del auto sacramental de Calderón El divino cazador», Anuario calderoniano, 13, 273-296.

SEBold, R. (1997): «'Mena y Garcilaso, nuestros amos'. Solís, Candamo, líricos neoclásicos». En Pérez Magallón, J. (ed.): Del Barroco a la Ilustración. Actas del Simposio celebrado en McGill University. Charlottesville: University of Virginia (Anejos Dieciocho. Hispanic-Enlightenment, 1), 155-173.

SuÁREZ, A. (1992): «Bances Candamo. Hacia un teatro ilustrado y polémico». Revista de Literatura, 109, 5-54.

Zugasti Zugasti, M. (2009): «Para la biografía de Bances Candamo. Documentación inédita en el archivo de los Duques de Alba». En Arellano Ayuso, I. et al. (eds.): Ars bene docendi. homenaje al profesor Kurt Spang. Pamplona: Eunsa, 597-612.

Zugasti Zugasti, M. (en prensa): «Epistolario inédito de Bances Candamo al Duque de Alba».

Davinia RODRÍGUEZ ORTEGA Universidad Pública de Navarra davinia.rodriguez@unavarra.es https://orcid.org/0000-0003-3179-0423 
